\title{
HEXALECTRIS WARNOCKII (ORCHIDACEAE): PRIMER REGISTRO PARA MEXICO
}

\author{
Gerardo A. Salazar Chavez \\ Herbario de la Asociación Mexicana de Orquideología, A.C. \\ Apartado Postal 53-123, 11320 México D.F., MEXICO
}

\begin{abstract}
RESUMEN
Se registra por primera vez la presencia en México de Hexalectris warnockii, orquídea terrestre áfila, anteriormente conocida sólo del sur de los E.U.A., sobre la base de una colección procedente de cerca del extremo sur de la Península de Baja California. Con tal adición todas las especies del género actualmente aceptadas se encuentran en México. Esta planta se distingue de sus congéneres principalmente por el labelo profundamente trilobado y con cinco lamelas muy prominentes, de las cuales tres llegan al ápice del lóbulo medio.
\end{abstract}

\section{ABSTRACT}

Hexalectris warnockii, a terrestrial leafless orchid formerly known only from southern U.S.A., is recorded for the first time in Mexico on the basis of a collection from near the southernmost end of the Peninsula of Baja California. With this record, all the species of the genus currently accepted are present in Mexico. This plant is distinguished among its relatives mainly by the deeply three-lobed lip with five prominent lamellae, of which three project to the apex of the mid-lobe.

El género Hexalectris Rafinesque consiste de 7 especies de orquídeas terrestres, saprófitas y carentes de hojas. Se encuentra distribuido principalmente en México y el sur de Estados Unidos, con una especie prolongándose hacia el norte hasta Virginia e llinois (Correll, 1941, 1950; Luer, 1975) y otra hacia el sur hasta Guatemala (Ames y Correll, 1953). Se trata de un grupo de plantas relativamente poco vistosas que frecuentemente pasan desapercibidas para los colectores y por ende no están bien representadas en los herbarios.

Hasta ahora hablan sido reconocidas 6 especies del género para México (Soto Arenas, 1989; Williams, 1951). Por otra parte, de las 5 especies adjudicadas a los Estados Unidos por Correll (1950) y por Luer (1975), sólo una, H. warnockii Ames \& Correll, no se habla encontrado en México.

En este trabajo se registra por primera vez la presencia de Hexalectris warnockii Ames \& Correll en México, con base en una colecta realizada recientemente por el personal del Centro de Investigaciones Biológicas de Baja California Sur, A.C. (CIB). La determinación del material se basó en una comparación con la descripción e ilustración originales (Ames y Correll, 1943) y otras referencias que incluyen descripciones, dibujos y/o fotografias (Correll, 1950; Luer,1975). Ningún representante de Hexalectris se habla mencionado antes para la flora de la Península de Baja California (Wiggins, 1980). Con esta comunicación, se muestra que todas las especies aceptadas del género se encuentran en México. 


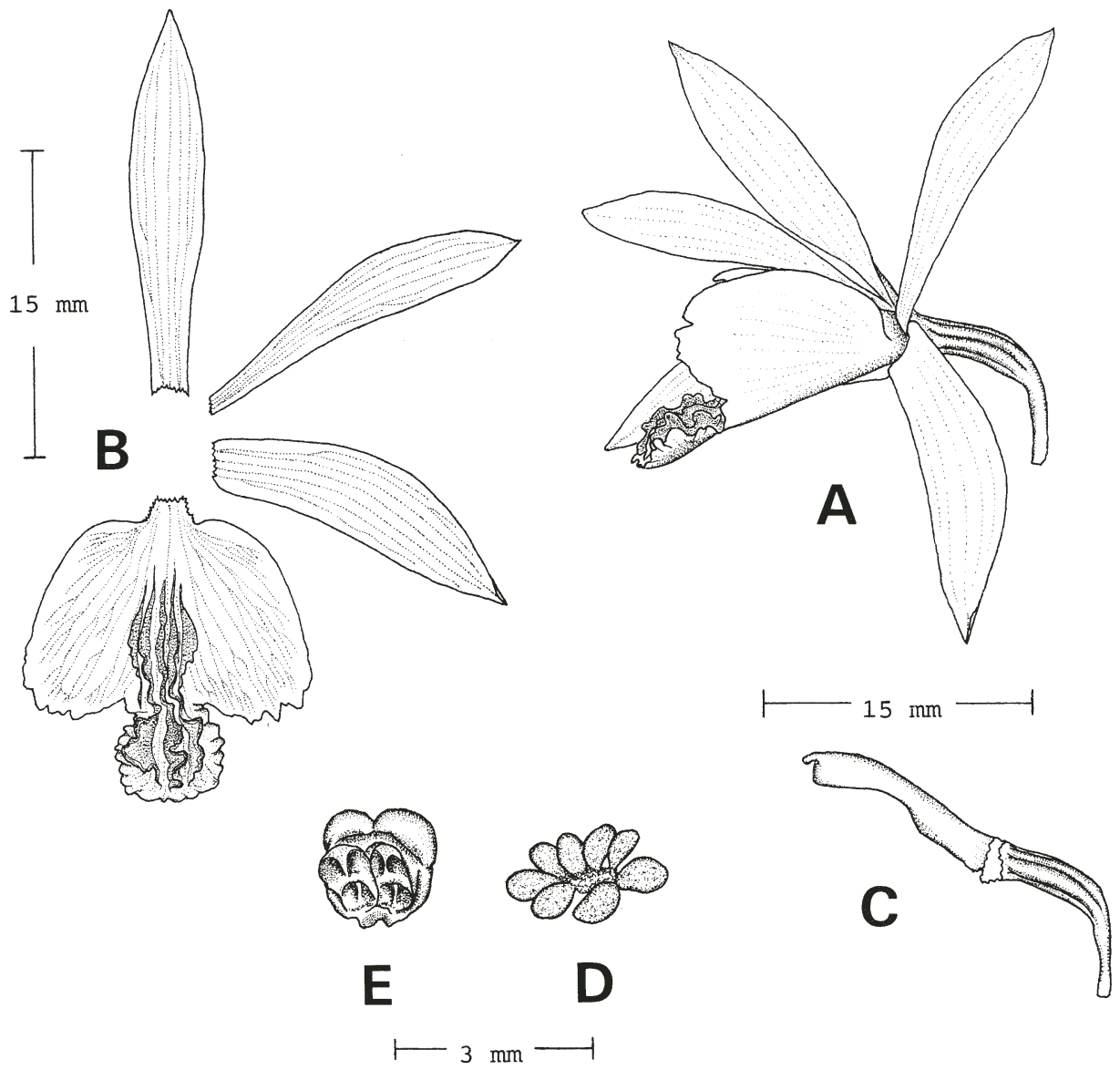

Fig. 1. Hexalectris warnockii. Análisis de una flor hidratada del ejemplar R. Dominguez C. 996. A. Aspecto general de la flor; B. Disección floral; C. Columna, vista lateral; D. Polinario; E. Antera, vista basal mostrando los lóculos. (Dibujo de G. A. Salazar).

Hexalectris warnockil Ames \& Correll, Bot. Mus. Leafl. Harv. Univ. 11(1): 8. 1943 (Fig. 1).

Descripción (basada en material mexicano): Hierba perenne, terrestre, saprofita, áfila, escaposa, completamente glabra, de $30-32 \mathrm{~cm}$ de alto (incluyendo la inflorescencia), originada a partir de un rizoma subterráneo, septado, rugoso, ramificado, de $2.5-5 \mathrm{~mm}$ de grosor, desnudo o cubierto por pequeñas catáfilas papiráceas de color pardo. Escapo erecto, delgado, aparentemente café-amarillento teńido de morado, de $20-22 \mathrm{~cm}$ de largo y 1.5-2.5 mm de grosor (en seco), con 2-3 brácteas tubulares, agudas, de $15-20 \mathrm{~mm}$ de 
largo. Inflorescencia racemosa, de pocas flores (4 en nuestro ejemplar), de 10-12 cm de largo; las flores espaciadas, todas dirigidas más o menos hacia el mismo lado del racimo, las flores inferiores abren primero, las superiores después, probablemente llegando a estar abiertas todas juntas. Brácteas florales ascendentes, ovado-elípticas, concavas, acuminadas, de 5.5-9 mm de largo. Flores vistosas, resupinadas, de $2.5-3 \mathrm{~cm}$ de diámetro (la flor inferior es la de mayor tamaño, decreciendo gradualmente las de más arriba), los sépalos y pétalos de color morado-rojizo, el labelo con la base y los lóbulos laterales rosamorado con venas y márgenes más obscuros, el lobbulo medio amarillo con el ápice moradorojizo. Ovario pedicelado, ascendente en la base, después abruptamente doblado para dar la posición final a la flor, de 9-13 $\mathrm{mm}$ de largo y $1.5-1.8 \mathrm{~mm}$ de grosor cerca del ápice, muy adelgazado hacia la base. Sépalos parcialmente extendidos, ligeramente incurvados, algo cóncavo-acanalados, el dorsal angostamente elíptico-oblanceolado, agudo, de 16.5$19.5 \mathrm{~mm}$ de largo y $3.5 \mathrm{~mm}$ de ancho, los laterales oblicuamente oblongo-oblanceolados, ligeramente falcados, cortamente acuminados, de $16-18 \mathrm{~mm}$ de largo y $4 \mathrm{~mm}$ de ancho. Pétalos parcialmente extendidos, algo incurvados, ligeramente convexos, oblanceoladoespatulados, someramente falcados, obtusos a agudos, de 16.5-18 mm de largo y 3-3.5 $\mathrm{mm}$ de ancho. Labelo cortamente adnado a la columna en la base por $1.5 \mathrm{~mm}$, ligeramente arqueado, profundamente trilobado, la base ampliamente redondeada, los lobbulos laterales erectos en posición natural, ocultando lateralmente la columna, de 14.5-15.5 mm de largo total y 14-16 mm de ancho entre los lóbulos laterales extendidos; lobulos laterales subovados, ampliamente redondeados, con el margen apical eroso-dentado, sobresaliendo 5.5-6 mm desde la unión con el lóbulo medio; lóbulo medio suborbicular a obovado, de ca. $5 \mathrm{~mm}$ de largo y ancho, los márgenes fuertemente ondulados, crenulados, el ápice muy ligeramente emarginado, con un pequeño apículo en el seno; la lámina del labelo entre los lóbulos laterales con 5 lamelas paralelas, irregularmente crenadas, las 2 laterales menos prominentes y terminando cerca de la base del lóbulo medio, las 3 centrales más prominentes y onduladas, prolongándose hasta casi el ápice del lobulo medio y siendo en esta estructura mucho más desarrolladas, irregulares y festoneadas. Columna delgada, ligeramente arqueada, con un ala poco prominente a cada lado del vientre un poco abajo de la mitad, de ca. $10 \mathrm{~mm}$ de largo y ca. $1.5 \mathrm{~mm}$ de ancho; el margen dorsal del clinandrio proyectado en un diente subcuadrado, carnoso, incurvado sobre la antera. Antera terminal, incumbente, subglobosa, con 2 lóbulos redondeados, imperfectamente 8-locular, de ca. $1.5 \mathrm{~mm}$ de largo y ancho. Polinario compuesto por 8 polinios subovoides, lateralmente comprimidos, amarillos, granulosos, unidos a una sola caudícula granulosa, amarilla, cada polinio de ca. $0.7 \mathrm{~mm}$ de largo. Rostelo formando una tira laminar semicircular, aparentemente con sustancia adhesiva en la superficie ventral. Cavidad estigmática suborbicular, cóncava. Cápsula no vista.

TIPO: E.U.A.: TEXAS: Brewster Co., rare in upper Blue Creek Canyon, Chisos Mts., June 25, 1937, B. H. Warnock, TEX (no visto).

Material examinado: BAJA CALIFORNIA SUR: "Los Güeribos", Cañón La Burrera, Todos Santos, $23^{\circ} 30^{\prime} \mathrm{N}, 109^{\circ} 59^{\prime} \mathrm{W}, 700 \mathrm{~m}$ alt.; selva baja caducifolia, ladera húmeda. Rara, perenne, flor modificada con amarillo y morado; 4 de agosto de 1990; $R$. Domínguez $C$. 996, AMO! 
Etimología: El epíteto honra a Barton Holland Warnock, botánico y colector texano quien encontró la especie en 1937.

Distribución: Suroeste de los Estados Unidos (Texas y Arizona); México (Baja California Sur).

Habitat: En Texas y Arizona ha sido localizada en cañones con comunidades de encino y de cedro-encino, sobre suelo calizo, hasta $2150 \mathrm{~m}$ de altitud (Correll, 1950; Luer, loc. cit.). En Baja California Sur fue encontrada en un cañón con selva baja caducifolia, a $700 \mathrm{~m}$ de altitud. Florece de junio a agosto.

Reconocimiento: Hexalectris warnockii se reconoce por sus escapos muy delgados en proporción al tamaño de las flores, el racimo laxo, con 4 a 8 flores de tamaño intermedio para el género, es decir, de unos $2.5-3 \mathrm{~cm}$ de diámetro natural, los sépalos y pétalos algo extendidos y ligeramente incurvados, de color morado-rojizo, y principalmente el labelo profundamente trilobado, con lamelas muy prominentes, de las que se presentan 5 en el centro de la lámina entre los lóbulos laterales, las dos exteriores poco desarrolladas y desvaneciéndose cerca de la base del lobulo medio, las 3 centrales muy prominentes y prolongándose casi hasta el ápice del lóbulo medio, muy festoneadas, dando al labelo cierto parecido con el de varias especies de Bletia. Los lóbulos laterales al extender son subovados, redondeados y con el margen apical eroso-dentado, de color rosado con los márgenes y las venas morados; el lóbulo medio es variable, suborbicular a obcordado o subcuadrado, ligeramente emarginado y con un pequeño apiculo en el seno apical, con los márgenes fuertemente ondulados e irregularmente crenados, de color amarillo con una mancha morada en la parte apical.

Comentarios: La planta mexicana corresponde bien al concepto de $H$. warnockii, encontrándose una discrepancia solamente debido a que en este material el labelo está cortamente adnado a la columna en la base, característica que no ha sido mencionada en referencia a $H$. warnockii ni en la descripción original ni en otras obras. Se desconoce si tal omisión se debe a que dicho atributo no se presenta en las plantas de Texas y Arizona o si ha pasado desapercibido, quedando pendiente su verificación cuando material auténtico 0 al menos procedente del suroeste de Estados Unidos pueda ser examinado en detalle.

Un aspecto adicional que llama la atención es la distribución aparentemente disyunta entre las poblaciones de Arizona y Texas y la de Baja California Sur, cerca del extremo sur de la península. Es de esperarse que a medida que se realice más exploración en el norte de México, una de las regiones del país menos conocidas en cuanto a la diversidad y distribución de la orquídeas (Soto Arenas, 1989), eventualmente se incrementará el área de distribución conocida de esta especie.

Se agradece al M. en C. J. L. León de la Luz, del CIB, por el obsequio al Herbario AMO del ejemplar en que se basa esta comunicación; también a E. Greenwood, E. Hágsater, V. Sosa y dos revisores anónimos por sus comentarios al manuscrito. 


\section{LITERATURA CITADA}

Ames, O. y D. S. Correll, 1943. Notes on American Orchids. Bot. Mus. Leafl. Harv. Univ. 11(1): 1-28. Ames, O. y D. S. Correll, 1953. Orchids of Guatemala. Fieldiana: Botany 26(2): 475-476.

Correll, D. S., 1941. Studies in Isochilus, Mormodes and Hexalectris. Bot. Mus. Leafl. Harv. Univ. 10(1): 1-20.

Correll, D. S., 1950. Native orchids of North America North of Mexico. Stanford University Press. Stanford, California. p. 324, fig. p. 323.

Luer, C. A., 1975. The native orchids of the United States and Canada excluding Florida. The New York Botanical Garden. New York. pp. 274-275.

Soto Arenas, M. A., (1988) 1989. Listado actualizado de las orquídeas de México. Orquídea (Méx.) 11: 233-276.

Wiggins, I. L., 1980. Orchidaceae. In: Flora of Baja California. Stanford University Press. Stanford, California. pp. 876-881.

Williams, L. O., 1951. The Orchidaceae of Mexico. Ceiba 2(1-4): 1-321. 